\title{
Dairy Biomass-Wyoming Coal Blends Fixed Gasification Using Air-Steam for Partial Oxidation
}

\author{
Gerardo Gordillo $^{1}$ and Kalyan Annamalai ${ }^{2}$ \\ ${ }^{1}$ Department of Mechanical Engineering, University of the Andes, Carrera 1 Este No. 19A-40, Office ML 652, Bogotá, Colombia \\ ${ }^{2}$ Department of Mechanical Engineering, Texas A\&M University, 307 Mechanical Engineering Office Building, College Station, \\ TX 77843, USA
}

Correspondence should be addressed to Gerardo Gordillo, g.gordillo43@uniandes.edu.co

Received 29 June 2011; Revised 8 November 2011; Accepted 30 November 2011

Academic Editor: Claes Tullin

Copyright ( 2012 G. Gordillo and K. Annamalai. This is an open access article distributed under the Creative Commons Attribution License, which permits unrestricted use, distribution, and reproduction in any medium, provided the original work is properly cited.

\begin{abstract}
Concentrated animal feeding operations such as dairies produce a large amount of manure, termed as dairy biomass (DB), which could serve as renewable feedstock for thermal gasification. DB is a low-quality fuel compared to fossil fuels, and hence the product gases have lower heat content; however, the quality of gases can be improved by blending with coals. This paper deals with air-steam fixed-bed counterflow gasification of dairy biomass-Wyoming coal blend (DBWC). The effects of equivalence ratio $(1.6<\Phi<6.4)$ and steam-to-fuel ratio $(0.4<S: F<0.8)$ on peak temperatures, gas composition, gross heating value of the products, and energy recovery are presented. According to experimental results, increasing $\Phi$ and $(S: F)$ ratios decreases the peak temperature and increases the $\mathrm{H}_{2}$ and $\mathrm{CO}_{2}$ production, while $\mathrm{CO}$ production decreases. On the other hand, the concentrations of $\mathrm{CH}_{4}$ and $\mathrm{C}_{2} \mathrm{H}_{6}$ were lower compared to those of other gases and almost not affected by $\Phi$.
\end{abstract}

\section{Introduction}

There is a growing interest in the development of alternatives to fossil fuel technologies in order to reduce both the dependence on fossil fuels (crude oil, coal, and natural gas) and the emissions generated by their wide spread usage. The conversion technology based on gasification has the advantages of being almost fuel independent compared to digestion and fermentation processes along with reduced grinding costs compared to suspension fired approach. Biomass fuels (e.g., energy crops, agricultural and forestry residues, and municipal, industrial, and animal wastes) can serve as a renewable feedstock for thermal gasification processes to produce gaseous fuels, which can be used for on situ clean power generation, since biomass is a neutral carbon fuel. Alternatively, by using catalysis or biocatalysis processes, the gaseous fuels produced could be converted to chemicals and liquid fuels.

Air gasification processes for coal and wood have been used for a long time to produce gaseous fuels for heat or power generation through internal combustion engines; however, only recently fundamental thermal gasification studies have been performed in order to improve the quality of the gaseous fuels produced. The quality (composition and heating value) of the product gases depends mainly on the type of fuel fed to the reactor, size of the reactor, and oxidizer used in the process as well as on the flow rates of both fuel and oxidizer via air and steam supplied simultaneously to the reactor. The most relevant gasifiers developed around the world have been fixed bed (updraft and downdraft), fluidized bed, and entrained flow $[1,2]$. The main difference of those reactors is the path followed by both the biomass and oxidizer within the reactor. This path affects both the resulting gas composition and the temperature profile along the reactor axis. The temperature profile is almost constant in the air blown gasifiers (fluidized bed and entrained flow) but presents a peak, which indicate the combustion region, in the fixed-bed gasifiers. The gas temperature leaving air blown down draft gasifiers is higher than that leaving a fixed-bed counterflow gasifier; therefore, the energy recovery efficiency within the bed for the fixed-bed updraft gasifiers is typically higher. 
Gasification of biomass with steam (e.g., steam reforming) is used to produce $\mathrm{H}_{2}$ enriched mixtures of $\mathrm{CO}_{2}$; however, this is an endothermic process which requires an external heat input, leading to lower gasification efficiencies. On the other hand, gasification of biomass with air-steam also produces mixtures rich in $\mathrm{H}_{2}$, but, in theory, this process can be carried out without additional heating, which implies higher efficiencies. Gasification with only air produces mixtures rich in $\mathrm{CO}$.

The main components of the gaseous fuel that result from gasification processes are $\mathrm{CO}, \mathrm{CH}_{4}, \mathrm{CO}_{2}, \mathrm{H}_{2} \mathrm{O}, \mathrm{H}_{2}$, $\mathrm{N}_{2}$, and trace amounts of light hydrocarbons in proportions that depend on many operating parameters. The main stages in gasification are drying, pyrolysis, partial oxidation, and reforming. They occur in all locations within the fluidizedand entrained-bed gasifiers, but they are separated in four different zones in fixed-bed gasifiers providing means for better control and process selectivity. Concentrated animal feeding operations (CAFOs) such as cattle feedlots and dairies produce a large amount of manure, cattle biomass (CB), and dairy biomass (DB) which may lead to land, water, and air pollution if waste handling systems for storage and treatment are not properly managed. It is estimated that, at any given time, there can be over 10 million of cattle heads present in feedlots in the United States [3], which could produce over 365 million of wet tons of manure per year since each animal can excrete about $27 \mathrm{~kg}$ of feedlot manure or feedlot biomass (FB) (including moisture) per day [4]. Full-grown milking cows can produce 7 to $8 \%$ of their body weight in manure per day that is, roughly 7.3 dry kg per animal per day. About 24 billion dry kg (26.7 million tons) of dairy manure is produced per year in the US [5]. If thermal gasification technology is developed for DB fuels, the environmental impact from both animal feeding operations and fossil fuels could be mitigated. DB which has high ash content $(14.95 \%)$ and low heating value $(12844 \mathrm{~kJ} / \mathrm{kg}$ as received basis) is a low-quality fuel compared to fossil fuels such as coal ( $\sim 21385 \mathrm{~kJ} / \mathrm{kg}$ as received basis) and natural gas $(\sim 50000 \mathrm{~kJ} / \mathrm{kg})$; however, the quality can be improved by blending with coals.

Some previous studies have focused on fixed-bed cattle biomass gasification using different operating conditions and various oxidizing sources. In 1980, Raman et al. [6] presented experimental results on fluidized-bed gasification of feedlot biomass (FB) using gases $\left(\mathrm{H}_{2} \mathrm{O}, \mathrm{O}_{2}\right.$, and $\left.\mathrm{CO}_{2}\right)$ produced by combustion of propane as oxidizing source. The effects of gasification temperature on yield, gas composition, and energy recovery were discussed. In 2005, Priyadarsan et al. [7] presented experimental results on adiabatic fixedbed gasification of feedlot biomass (FB) and Wyoming coal-feedlot biomass blends using air for partial oxidation. Two different particle sizes and two air flows were tested under non-steady-state conditions of the bed since ash is not removed from the bed. In 2009, Gordillo et al. [8] presented results from equilibrium and atom balance modeling studies on dairy biomass (DB) and feedlot biomass (FB) gasification using air-steam for partial oxidation. They [8] defined modified equivalence ratio, $\mathrm{ER}_{M}$, as the ratio of stoichiometric oxygen mass to the total actual oxygen input from both air and steam; the $\mathrm{ER}_{M}$ is different from the conventional equivalence ratio $(\Phi)$ since $\Phi$ includes the oxygen input only from air. The effects of both $\mathrm{ER}_{M}$ and $\Phi$ on temperature profile, gas composition $\left(\mathrm{CO}, \mathrm{CO}_{2}, \mathrm{H}_{2}, \mathrm{~N}_{2}\right.$, $\mathrm{CH}_{4}$, and $\mathrm{C}_{2} \mathrm{H}_{6}$ ), gross or higher heating value (HHV), and energy conversion efficiency were discussed. Subsequently, experimental results were presented for adiabatic fixed-bed gasification of pure DB using air and steam as oxidizing source and under steady state conditions $[9,10]$.

It is concluded from the literature review that there is no previous work on fixed-bed gasification of DB-WYC blends and their effects on enhancement of gross heat value of product gases which include a fraction of volatile matter (VM) as released and the gases produced as a result of exothermic and endothermic reactions of VM with other species, $\mathrm{CO}$ and $\mathrm{CO}_{2}$, produced as result of char oxidation, and $\mathrm{H}_{2}$. The higher the HHV of VM, the higher the heat value of product species. Particularly the heat value of VM from coal is higher than that of VM from DB. Thus, the product gases from coal-DB blend are expected to have higher quality of gases. The current paper deals with gasification of dairy biomassWyoming coal blend (DBWC) using air-steam mixtures as oxidizing source and a small-scale $(10 \mathrm{~kW})$ fixed-bed updraft gasifier. Experimental results on temperature profile, gas composition of species such as $\mathrm{CO}, \mathrm{CO}_{2}, \mathrm{H}_{2}, \mathrm{CH}_{4}$, and $\mathrm{C}_{2} \mathrm{H}_{6}$, and higher heat values (HHV) are presented and compared with results from pure DB in order to validate the proposed hypothesis of the enhanced quality of product gases. A mass spectrometer was used to analyze gas composition at real time and continuously. The HHV of the product gases and the energy conversion efficiency (ECE) are also presented. The conventional equivalence ratio $(\Phi)$ is defined as the ratio of the stoichiometric oxygen moles to actual oxygen moles while the steam-to-fuel ratio $(S: F)$ is defined as the ratio of moles of steam-to-fuel moles (1):

$$
\begin{aligned}
\Phi & =\frac{\text { Stoichiometric air moles }}{\text { actual air moles }} \\
& =\frac{\text { Stoichiometric } \mathrm{O}_{2} \text { moles }}{\text { actual } \mathrm{O}_{2} \text { moles }}=\frac{a}{e}, \\
S: F & =\frac{\mathrm{kmol} \text { of steam }}{\text { kmol of empirical DAF fuel }}=f,
\end{aligned}
$$

where $a$ corresponds to the moles the oxygen required for complete combustion of an empirical fuel mole and $e$ and $f$ the oxygen moles and steam moles supplied to the gasifier for partial oxidation of an empirical fuel mole.

\section{Materials and Methods}

2.1. Experimental Facility. The experiments were developed using a small-scale $(10 \mathrm{~kW})$ gasification facility composed of a batch-type counterflow gasifier, K-type thermocouples to measure the temperature at 8 locations along the gasifier axis, an ash disposal system so that the experiments could be run continuously under steady state conditions with periodic ash disposal, a steam generator to produce the steam supplied to the gasifier, a sampling system to prepare the 
samples (retain tar and particulate material) to be analyzed at real time and continuously by a mass spectrometer (MS), a data acquisition system to store the temperature, and a control panel to control the flows of steam, air, and heat supplied to the heater elements placed in the steam generator and the gasifier combustion chamber. A schematic of the gasification facility was presented in a previous publication [9], and it is also available elsewhere [8]. All the experiments were carried out adiabatically and started with a preheating routine for the empty gasifier (i.e., without biomass). When the temperature at $\sim 2 \mathrm{~cm}$ above the grate achieved $\sim 800^{\circ} \mathrm{C}$, biomass was added gradually to the gasifier until the bed height increased to $17 \mathrm{~cm}$, at this point, the fuel port was closed and the flows of steam and air were adjusted to the desired experimental conditions. As the biomass was pyrolyzed and the char was burned, the bed height started decreased and ash accumulated. Thus, biomass was added every $10 \mathrm{~min}$ and in batches to maintain a constant flow rate of $1 \mathrm{~kg} / \mathrm{h}$ whereas the flow rates of air $\left(0.56-2.26\right.$ SATP $\left.\mathrm{m}^{3} / \mathrm{h}\right)$ and steam $(0.19-0.43 \mathrm{~kg} / \mathrm{h})$ at $100^{\circ} \mathrm{C}$ were changed in order to obtain the desired experimental conditions $(1.6<\mathrm{ER}$ $<6.4$ and $0.4<S: F<0.8)$. The ash was disposed off continuously from the bed to the plenum using a vibrator at the bottom of the grate. This was necessary to keep both the peak temperature $\left(T_{\text {peak }}\right)$ at the same location and constant bed height. If ash is not disposed off periodically, the peak temperature will move toward the free surface due to ash accumulation and steady state cannot be maintained [7].

It is noted that shallow bed height will lead to gases leaving at higher temperatures, thus loosing sensible heat. With increased bed height, one provides more residence time for both the solid and gas phase reactions to proceed with increased concentration of species and reduced temperature of gases leaving the bed (Figure 3). The bed height may be selected such that the temperature of gases leaving the bed is well above the saturation temperature of $\mathrm{H}_{2} \mathrm{O}$ so that enough temperature difference exists between solid and gas phases to drive off the moisture. Typically the bed height can be varied by altering the feed rates of fuel and hence the thermal rating of the bed. For the current problem, same thermal rating is maintained at about $10 \mathrm{~kW}$ with constant fuel feed rate. When the gasifier achieved steady-state conditions, the temperatures were measured and stored at every 10 seconds, and the gas sampling unit was turned on to analyze continuously the gas samples by the MS during 20 minutes. The ash was analyzed to determine its composition (results on ash composition are presented elsewhere $[10,11])$.

2.2. Fuel Properties. The fuel was supplied by the Texas A\&M Agrilife Research and Extension Center at Amarillo, Texas. The DB-water slurry from dairies was sent to a separator where DB solids were separated from slurry, then composted and partially crushed to provide a coarse grain of $6.35 \mathrm{~mm}$ $\left(1 / 4^{\prime \prime}\right)$ of average particle size. The properties of the fuels were characterized by ultimate and proximate analyses on an as-received basis of pure DB and pure WYC, including heating values (HHV). The properties of DBWC blend ( $90 \%$ DB and 10\% WYC ) were determined using the properties of

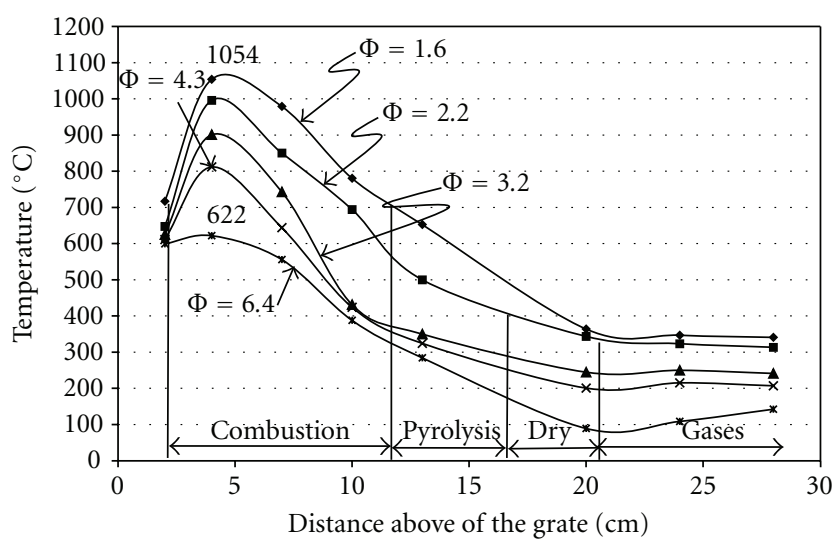

FIGURE 1: Temperature profile along the gasifier axis for gasification of DBWC blend at $S: F=0.4$, adapted from [11].

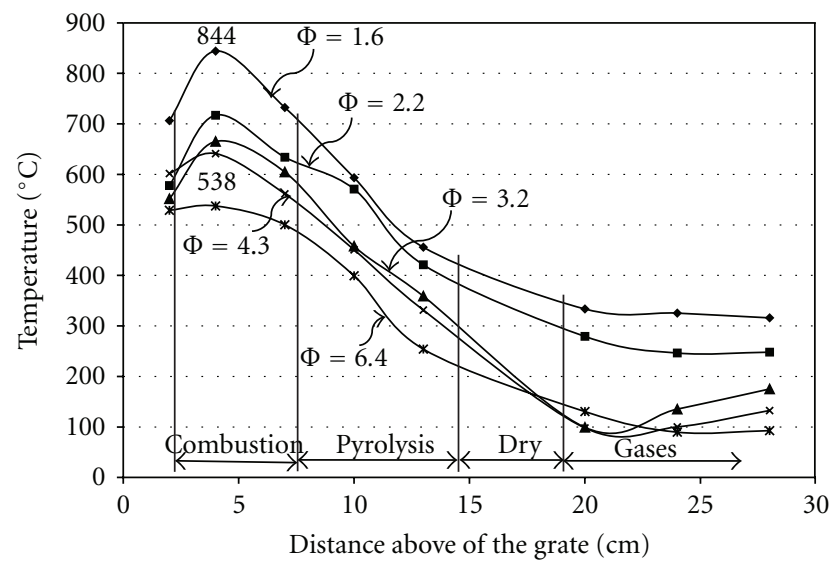

FIGURE 2: Temperature profile along the gasifier axis for gasification of DBWC blend at $S: F=0.80$, adapted from [11].

pure DB and WYC and mass balance on compounds. Table 1 presents proximate and ultimate analysis of DB, WYC, and DBWC. Using ultimate and proximate analysis and atom balance on compounds, the empirical formulas for each fuel were derived as shown in Table 1. The analysis shows that (i) the HHV of DBWC $(13698 \mathrm{~kJ} / \mathrm{kg})$ is higher than that of the pure DB $(12844 \mathrm{~kJ} / \mathrm{kg})$, (ii) the HHV of VM for blend is higher than that of pure, DB and (iii) the FC of blend is higher that of pure DB yielding more CO.

2.3. Experimental Conditions. Table 2 shows the experimental conditions. DBWC fuel, composed of $90 \%$ DB and $10 \%$ WYC (as received), was used as feedstock in the experiments. Dry air at $25^{\circ} \mathrm{C}$ and steam at $100^{\circ} \mathrm{C}$ were blended and supplied to the plenum of the gasifier at the flow rates required to keep $\Phi$ and $S: F$ at the desired experimental ranges which were chosen on the basis of results obtained in previous modeling studies [8]. The experiments were performed without any external heat input (almost adiabatically) and at a vacuum pressure of $39 \mathrm{~Pa}$. The adiabaticity of the gasifier was verified by finding experimentally the overall heat transfer coefficient $(U)$ and determining the heat 
TABLE 1: Ultimate and proximate analysis on an as received basis.

\begin{tabular}{|c|c|c|c|}
\hline Fuel name & Wyoming coal (WYC) & Dairy biomass (DB) & DBWC (90:10) \\
\hline Dry loss $(\%)$ & 22.81 & 25.26 & 25.015 \\
\hline Ash (\%) & 5.45 & 14.95 & 14.00 \\
\hline VM (\%) & 34.5 & 46.84 & 45.606 \\
\hline $\mathrm{FC}(\%)$ & 37.25 & 12.95 & 15.38 \\
\hline $\mathrm{VM}_{\mathrm{DAF}}(\%)$ & 48.00 & 78.00 & 74.78 \\
\hline $\mathrm{FC}_{\mathrm{DAF}}(\%)$ & 52.00 & 22.00 & 25.22 \\
\hline $\mathrm{C}(\%)$ & 54.07 & 35.27 & 37.15 \\
\hline $\mathrm{H}(\%)$ & 3.44 & 3.1 & 3.13 \\
\hline $\mathrm{N}(\%)$ & 0.81 & 1.9 & 1.791 \\
\hline $\mathrm{O}(\%)$ & 13.08 & 19.1 & 18.498 \\
\hline $\mathrm{S}(\%)$ & 0.39 & 0.42 & 0.417 \\
\hline $\mathrm{HHV}(\mathrm{kJ} / \mathrm{kg})$ & 21385 & 12844 & 13698 \\
\hline DAF HHV (kJ/kg) & 29809 & 21482 & 22461 \\
\hline Dry HHV (kJ/kg) & 27704 & 17185 & 18237 \\
\hline Empirical formulae & $\mathrm{CH}_{0.76} \mathrm{~N}_{0.013} \mathrm{O}_{0.18} \mathrm{~S}_{0.003}$ & $\mathrm{CH}_{1.06} \mathrm{~N}_{0.047} \mathrm{O}_{0.405} \mathrm{~S}_{0.0045}$ & $\mathrm{CH}_{1.03} \mathrm{~N}_{0.043} \mathrm{O}_{0.39} \mathrm{~S}_{0.001}$ \\
\hline Estimated HHV of VM $(\mathrm{kJ} / \mathrm{kg})^{+}$ & 26607 & 18300 & 18986 \\
\hline
\end{tabular}

${ }^{+}$Estimated using eq. HHVDAF of fuel [12] $=$HHV of VM $*$ VMDAF + HV of FC $*$ FCDAF; HV of FC $=32765 \mathrm{~kJ} / \mathrm{kg}$.

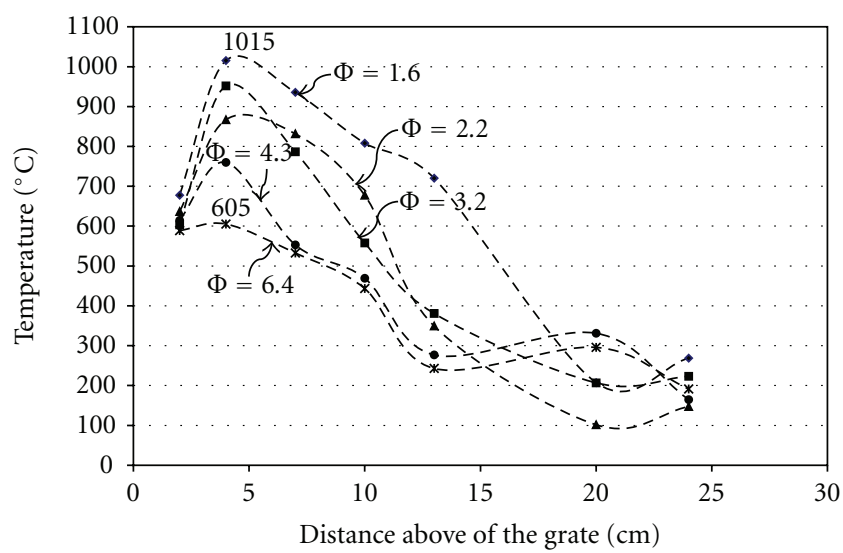

FIGURE 3: Temperature profile along the gasifier axis for gasification of pure, DB at $S: F=0.4$, adapted from [11], also available in [10].

loss. Details of the experiments performed to determine $U$ are given in [11]. All the experiments were performed at a constant DB particulate size of $\sim 6.35 \mathrm{~mm}$. Equation (1) define the parameters investigated ( $\Phi$ and $S: F$ ) in this study.

As discussed before, an MS was used to analyze CO, $\mathrm{CH}_{4}, \mathrm{~N}_{2}, \mathrm{H}_{2}, \mathrm{C}_{2} \mathrm{H}_{6}$, and $\mathrm{CO}_{2}$ at real time and continuously. The MS was calibrated every 72 hours for overlapping, linearity, and sensitivity. The calibration was verified by measuring known standard mixtures. Data uncertainty in the gas composition was determined by calculation of standard deviations. Uncertainty for each gas was calculated as the ratio between the standard deviation and the average measurement. Additionally, uncertainty for temperatures was estimated as the ratio between the uncertainty of the device
TABLE 2: Experimental conditions.

\begin{tabular}{lc}
\hline Parameter & \\
\hline Fuel & DBWC \\
Pressure $(\mathrm{Pa})$ & 36 \\
Air temperature ${ }^{\circ} \mathrm{C}$ & 25 \\
Steam temperature ${ }^{\circ} \mathrm{C}$ & 100 \\
$\Phi$ & $1.6-6.4$ \\
$S: F$ & 0.40 and 0.80 \\
Bed height $(\mathrm{cm})$ & 17 \\
Gases measured & $\mathrm{CO}, \mathrm{CO}_{2}, \mathrm{CH}_{4}, \mathrm{~N}_{2}, \mathrm{H}_{2}$, and $\mathrm{C}_{2} \mathrm{H}_{6}$ \\
Particulate size $(\mathrm{mm})$ & 6,35
\end{tabular}

$\left( \pm 1.5^{\circ} \mathrm{C}\right)$ and the measured value. In general the uncertainty in the gases lied within $\sim 15 \%$ and the temperature within $0.55 \%$.

\section{Results and Discussion}

3.1. Temperature Profiles. Figures 1 and 2 show the results on the steady state temperature profile for $1.6<\Phi<$ 6.4 and $S: F=0.40$ and $S: F=0.80$. The results show a peak temperature near the bottom of the bed in the combustion zone where the heterogeneous reactions $\mathrm{C}+$ $\mathrm{O}_{2} \rightarrow \mathrm{CO}_{2}, \mathrm{C}+1 / 2 \mathrm{O}_{2} \rightarrow \mathrm{CO}$, and $\mathrm{C}+\mathrm{H}_{2} \mathrm{O} \rightarrow \mathrm{CO}+\mathrm{H}_{2}$ occur. The partial and complete oxidation of char that lead to $\mathrm{CO}$ and $\mathrm{CO}_{2}$ production respectively, are highly exothermic reactions; thus, the heat required to drive the gasification process is self generated. Since the oxidation rate of large particles of char is almost diffusion controlled, the peak 


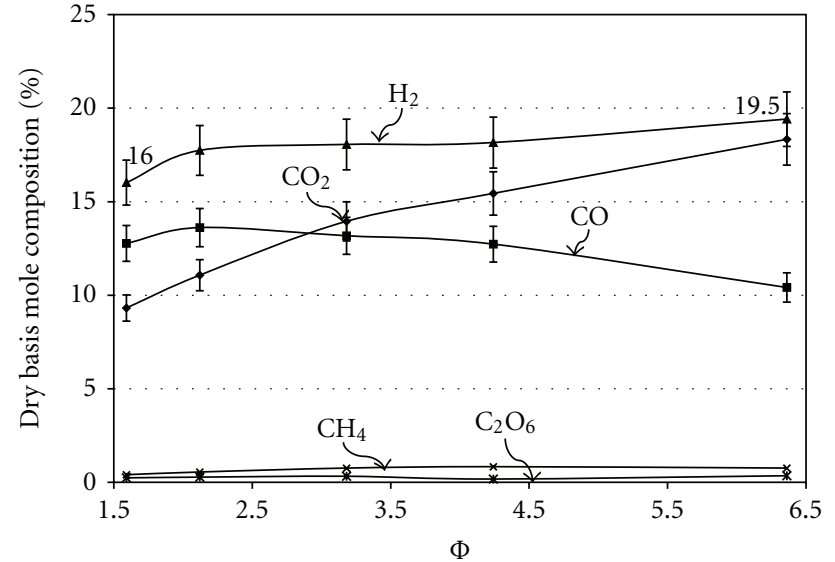

Figure 4: Gas composition of DBWC gasification at $S: F=0.40$ and several $\Phi$ (figure adapted from [11]).

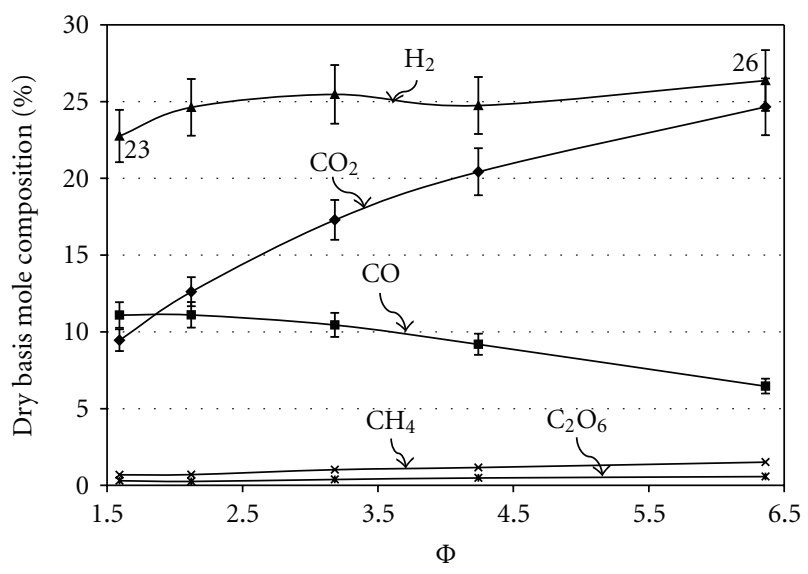

Figure 5: Gas composition of DBWC gasification at $S: F=0.80$ and several $\Phi$ s, adapted from [11].

temperature $\left(T_{\text {peak }}\right)$ depends upon the availability of $\mathrm{O}_{2}$, $\mathrm{H}_{2} \mathrm{O}$ and $\mathrm{CO}_{2}$ in the combustion zone.

In general, the results show that $T_{\text {peak }}$ is located $\sim 4 \mathrm{~cm}$ above the grate for the operating experimental conditions $(S$ : $F=0.4$ and $S: F=0.80$ and $1.6<\Phi<6.4$ ). This fixed location is possible because of the continuous ash disposal from the bed to the gasifier plenum.

The effect of $\Phi$ and $S: F$ on $T_{\text {peak }}$ is illustrated on Figures 1 and 2. Increasing $\Phi$ and $S: F$ results in decreased $T_{\text {peak }}$. At constant $\Phi$, increasing $S: F$ implies more steam entering to the gasifier; thus, the reaction $\mathrm{C}+\mathrm{H}_{2} \mathrm{O} \rightarrow \mathrm{CO}+\mathrm{H}_{2}$, which is endothermic, is favored (e.g., at $\Phi=1.6$ and $S: F=0.4 T_{\text {peak }}=1054^{\circ} \mathrm{C}$ whereas at $\Phi=1.6$ and $S$ : $F=0.8 T_{\text {peak }}=844^{\circ} \mathrm{C}$ ). At fixed $S: F$, increasing $\Phi$ implies reduced oxygen supply and hence reduced exothermic heat and peak temperature in the bed.

The temperature profile of pure DB is shown in Figure 3 for $S: F=0.40$ and $1.6<\Phi<6.4$. As discussed before, $T_{\text {peak }}$ depends mostly of steam $(S: F)$ and $\mathrm{O}_{2}(\Phi)$ concentration in the combustion region. Comparing Figures 1 and 3, it is apparent that the addition of WYC increases $T_{\text {peak }}$ (e.g.,

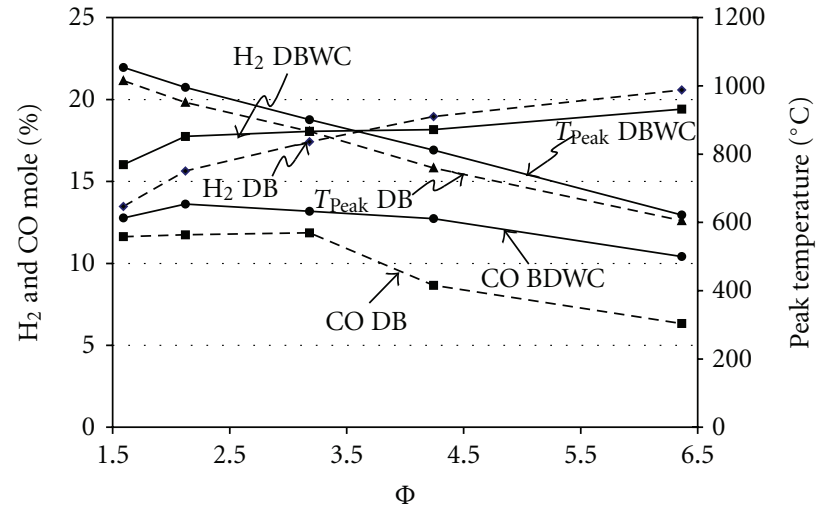

Figure 6: Comparison between $\mathrm{H}_{2}$ and $\mathrm{CO}$ produced by gasification of DBWC and DB at $S: F=0.4$, curves of DB adapted from [11].

at $\Phi=1.6$ the $T_{\text {peak }}$ of DBWC is about $30^{\circ} \mathrm{C}$ higher than $T_{\text {peak }}$ of pure $\left.\mathrm{DB}\right)$. This could be due to the decrease of the bed porosity (void fraction) in the combustion region since the particle size of DB $(6.35 \mathrm{~mm})$ is higher than that of WYC $(0.5 \mathrm{~mm})$. This is because WYC particles, whose particle size is smaller than that of DB, lie between larger sized DB particles decreasing porosity and increasing gas velocity. Increased velocity means improving heat and mass transfer between the gases and DB particles; hence, the fuel burning rate increases per unit of volume. This causes higher heat generation in the oxidation zone, which leads to a higher temperature. Since the gasifier was fed in batches, the curves of the gas stream region lack a consistent trend; thus, the effect of the WYC addition is not clear near the bed surface.

3.2. Gas Composition. Once a steady-state condition was achieved (i.e., $T_{\text {peak }}$ did not change the value or location), gas samples were withdrawn from the top of the gasifier and analyzed at real time and continuously using a mass spectrometer (MS) calibrated to measure $\mathrm{CO}, \mathrm{CO}_{2}, \mathrm{H}_{2}, \mathrm{CH}_{4}$, $\mathrm{C}_{2} \mathrm{H}_{6}, \mathrm{~N}_{2}$, and $\mathrm{O}_{2}$. The gas analysis was performed at steadystate condition during 20 minutes to decrease the uncertainty of results, which results in an average uncertainty of value of $\sim 15 \%$. The results on gas composition discussed in this paper correspond to the average measured during the last ten minutes of each experiment. For all the experiments the gas analysis did not show presence of $\mathrm{O}_{2}$. Figures 4 and 5 show the mole percentage (dry basis) of $\mathrm{H}_{2}, \mathrm{CO}_{2}, \mathrm{CO}, \mathrm{CH}_{4}, \mathrm{C}_{2} \mathrm{H}_{6}$ for $S: F=0.4$ and $S: F=0.80$ and various equivalence ratios $(\Phi)$.

From the results, it is apparent that, at constant $S: F$, increasing $\Phi$ results in an increase in the $\mathrm{H}_{2}$ and $\mathrm{CO}_{2}$ productions but $\mathrm{CO}$ concentrations are lower. Increasing $\Phi$ decreases $T_{\text {peak }}$ in the combustion zone where the reactions $\mathrm{C}+\mathrm{O}_{2} \rightarrow \mathrm{CO}_{2}$ and $\mathrm{C}+1 / 2 \mathrm{O}_{2} \rightarrow \mathrm{CO}$ occur, which results in favored conversion to $\mathrm{CO}_{2}$ with consequent low CO concentrations [12]. Also, at constant $S: F$, increased $\Phi$ implies less oxygen entering to the gasifier with the air, and hence the fuel oxidation process occurs in an ambient rich in $\mathrm{H}_{2} \mathrm{O}$ which favors the reaction $\mathrm{C}+\mathrm{H}_{2} \mathrm{O} \rightarrow \mathrm{CO}+\mathrm{H}_{2}$. 
TABLE 3: Energy density of gases on a dry basis $\left(\mathrm{kJ} / \mathrm{SATPm}^{3}\right)$ as a function of $\Phi$ and various $S$ : $F$ ratios for DB and DBWC, adapted from [11].

\begin{tabular}{|c|c|c|c|c|c|c|c|c|c|c|}
\hline \multirow{3}{*}{$S: F$} & \multicolumn{10}{|c|}{$\Phi$} \\
\hline & \multicolumn{2}{|c|}{1.6} & \multicolumn{2}{|c|}{2.2} & \multicolumn{2}{|c|}{3.2} & \multicolumn{2}{|c|}{4.3} & \multicolumn{2}{|c|}{6.4} \\
\hline & $\mathrm{DB}$ & DBWC & DB & DBWC & DB & DBWC & DB & DBWC & $\mathrm{DB}$ & DBWC \\
\hline 0.40 & 3280 & 3649 & 3473 & 4023 & 3787 & 4115 & 3648 & 4007 & 3666 & 3972 \\
\hline 0.80 & 3934 & 4377 & 4116 & 4573 & 4291 & 4793 & 4378 & 4679 & 4585 & 4738 \\
\hline
\end{tabular}

TABLe 4: Energy conversion efficiency (ECE) as a function of the $\Phi$ and various $S: F$ ratios, adapted from [11].

\begin{tabular}{lccccc}
\hline$S: F$ & \multicolumn{5}{c}{$\Phi$} \\
& 1.6 & 2.2 & 3.2 & 4.2 & 6.4 \\
\hline 0.4 & 0.7 & 0.64 & 0.48 & 0.37 & 0.26 \\
0.8 & 0.77 & 0.70 & 0.58 & 0.46 & 0.35 \\
\hline
\end{tabular}

However, the $\mathrm{CO}$ produced by this reaction is consumed by the water-gas shift reaction $\left(\mathrm{CO}+\mathrm{H}_{2} \mathrm{O} \rightarrow \mathrm{H}_{2}+\mathrm{CO}_{2}\right)$ to produce more $\mathrm{CO}_{2}$ and $\mathrm{H}_{2}$.

Figure 5 shows that increased $S: F$ at constant $\Phi$ increases the production of $\mathrm{H}_{2}$ and $\mathrm{CO}_{2}$ and decreases $\mathrm{CO}$. The steam supplied to the gasifier increases with increased $S: F$; therefore, there is more $\mathrm{H}_{2} \mathrm{O}$ available for the reactions $\mathrm{C}+$ $\mathrm{H}_{2} \mathrm{O} \rightarrow \mathrm{CO}+\mathrm{H}_{2}$ in the combustion zone and $\mathrm{CO}+\mathrm{H}_{2} \mathrm{O} \rightarrow$ $\mathrm{H}_{2}+\mathrm{CO}_{2}$ in the reduction, pyrolysis, dry, and stream gas zones. Competing reactions are present for $\mathrm{CO}$ while $\mathrm{CO}_{2}$ and $\mathrm{H}_{2}$ have an increasing trend. The effect of the $\Phi$ and $S: F$ on the production of the hydrocarbons $\left(\mathrm{CH}_{4}\right.$ and $\left.\mathrm{C}_{2} \mathrm{H}_{6}\right)$ is insignificant. On the other hand, the results show that the effect of the $S$ : $F$ on the $\mathrm{H}_{2}$ production is more important than that of the equivalence ratio $(\Phi)$. For example, at $S: F=0.4$ and $S: F=0.8$, increasing $\Phi$ from 1.6 to 6.4 increases the $\mathrm{CO}$ moles by about $3 \%$ whereas increasing $S: F$ from 0.4 to 0.8 increases the $\mathrm{H}_{2}$ production by about $7 \%$. In general for this set of experiments, there were mixtures with $\mathrm{CO}$ ranging between 6.5 and $13.6 \%$ and $\mathrm{H}_{2}$ ranging between 16 and $26.3 \%$. The $\mathrm{CH}_{4}$ and $\mathrm{C}_{2} \mathrm{H}_{6}$ productions ranged from 0.4 to $1.5 \%$ and 0.25 to $0.60 \%$, respectively.

Figure 6 illustrates the effect of adding WYC to DB on

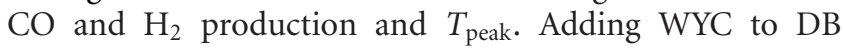
contributes to increase the HHV and void fraction of the fuel; thus, the temperature in the combustion region $\left(T_{\text {peak }}\right)$ also increases. Increased $T_{\text {peak }}$ tends to increase the char oxidation rate to produce $\mathrm{CO}$ instead of $\mathrm{CO}_{2}$ [12]. In general, the presence of WYC increased $T_{\text {peak }}$ and the CO production by about $4.5 \%$ and $25 \%$ (average), respectively. The effect of adding WYC on the $\mathrm{H}_{2}$ production is important at $\Phi<$ 3.6 but at $\Phi>3.6$ it seems to be insignificant. Also, it is apparent that WYC addition affects more the CO production at $\Phi>3.2$ than at $\Phi<3.2$. This seems to indicate that, at $\Phi<3.2$, the WYC addition favors the reaction rate of the shift reaction $\left(\mathrm{CO}+\mathrm{H}_{2} \mathrm{O} \rightarrow \mathrm{CO}_{2}+\mathrm{H}_{2}\right)$ whereas at $\Phi>3.2$ the effect of WYC addition on the shift reaction seems to be negligible. It could not be ascertained whether the effect on the shift reaction rate is due to temperature effect (physical) or catalytic (chemical) effect. The maximum increase in $\mathrm{H}_{2}$ production $(\sim 19 \%)$ by WYC addition was achieved at $\Phi=1.6$.

3.3. HHV of Gases. The HHV or energy density of the gases was calculated using (2).

$$
\mathrm{HHV}_{\text {gas }}=\sum_{i}\left(X_{i} \times \mathrm{HHV}_{i}\right),
$$

where $X_{i}$ and $\mathrm{HHV}_{i}$ are mole fraction and gross heating value of species " $i$ " ( $i=\mathrm{CO}, \mathrm{CH}_{4}, \mathrm{H}_{2}$, etc.) in kJ per SATP $\mathrm{m}^{3}$ of dry gaseous fuel species " $i$ " leaving the gasifier. The $\mathrm{HHV}_{\text {gas }}$ is the $\mathrm{HHV}\left(\mathrm{kJ}\right.$ per SATP $\mathrm{m}^{3}$ ) of the product gas mixture.

Table 3 presents the energy density of the gases at $1.6<$ $\Phi>6.4$ and $S: F=0.4$ and 0.8 , respectively. The results indicate that increased $S: F$ increases the gross heating value of the gases; this is due principally to the increase in the production of hydrocarbons and $\mathrm{H}_{2}$. At constant $S: F$, increasing $\Phi$ tends to increase the HHV until certain $\Phi$ beyond which it starts to decrease. The HHV for the selected operating conditions varied from 3649 to $4793 \mathrm{~kJ} / \mathrm{SATP} \mathrm{m}^{3}$. The highest HHV $\left(4793 \mathrm{~kJ} / \mathrm{SATP} \mathrm{m}^{3}\right)$ was measured at $\Phi=$ 3.2 and $S: F=0.80$ whereas the lowest HHV was measured at $\Phi=1.6$ and $S: F=0.4$. From Table 3 it is evident that the effect of $S: F$ ratio on HHV of gases is stronger than that of $\Phi$. From Table 3, it is evident that the energy density of the product gases which results from DBWC gasification is higher than that of the gases produced from DB gasification.

3.4. Energy Conversion Efficiency. The energy conversion efficiency (ECE), or energy recovery, was calculated using yield of gases, energy density of the gases, and (3)

$$
\begin{aligned}
& \text { ECE } \\
& =\frac{\mathrm{HHV}_{\text {gases }}}{N_{\text {fuel }} \times \mathrm{HHV}_{\text {fuel }}+N_{S} \times M_{S} \times\left(\lambda+C_{p} \times\left(T_{S}-T_{a}\right)\right)},
\end{aligned}
$$

where $N_{\text {fuel }}$ and $N_{s}$ correspond to the moles of fuel and steam supplied, respectively, to the gasifier by each SATP $\mathrm{m}^{3}$ of dry product gases, $\lambda$, latent heat of steam $(\mathrm{kJ} / \mathrm{kg} \cdot \mathrm{K}), \mathrm{HHV}_{\text {fuel }}$, gross heat value $\left(\mathrm{kJ} \mathrm{kmol}^{-1}\right.$ of DAF (dry ash free) empirical fuel), $M_{S}=$ molar mass of steam $(\mathrm{kg} / \mathrm{kmol}), C_{p}$, steam heat specific $(\mathrm{kJ} / \mathrm{kg} \cdot \mathrm{K}), T_{s}$, steam temperature, and $T_{a}$, ambient temperature.

Due to the impossibility of measuring the mass of tar produced during the experimentation, the yield gas, required to calculate the energy recovery, was estimated by mass 
balance using the compositions of tar and gases. The results on ECE are presented in Table 4 for $S: F=0.40$ and $S: F=0.80$ and several $\Phi$. The ECE increases with increased $S: F$ ratios but decreases with increased $\Phi$. This is due to the fact that increased $\Phi$ implies insufficient oxygen for complete oxidation of char, and hence lower amounts of combustible gases are produced and more fuel is lost through the char per fuel unit. Ultimate and proximate analyses were performed on tar to determine its composition. Details of tar content in gases, char content in ash, and tar composition (elemental composition) obtained by ultimate analysis are given in [11]. The ECE discussed in this paper ranged from $26 \%$ to $77 \%$ and is a little higher than that presented in previous works [6] for nonadiabatic fluidized bed gasification of FB (0.20$0.60)$. This agrees with the fact that in an updraft fixed-bed gasifier the sensible heat loss of the gases leaving the gasifier is lower than that of the gases leaving a fluidized-bed gasifier.

\section{Conclusions}

(1) $T_{\text {peak }}$ in the combustion region lies $\sim 4 \mathrm{~cm}$ above the grate and decreases with increased $\Phi$ and $S: F$ ratios. Gasification of DBWC at $\Phi s>6.4$ and $S: F>0.8$ could lead to lower temperatures than that required to burn the char; thus, the process under those conditions tends to be pure pyrolysis to produce char and fuel gases with high tar content.

(2) Increased $\Phi$ and $S: F$ ratios produce mixtures rich in $\mathrm{H}_{2}$ and $\mathrm{CO}_{2}$ but poor in $\mathrm{CO}$. In general for the set of experiments presented here, the $\mathrm{CO}$ ranged from 6.5 to $13.6 \%$ and the $\mathrm{H}_{2}$ from 16 to $26.3 \%$.

(3) The addition of WYC increased $T_{\text {peak }}$ and CO by about $4.5 \%$ and $25 \%$, respectively, compared to the $T_{\text {peak }}$ and the CO obtained from pure DB.

(4) The effect of the $S: F$ ratio on HHV of the gases is more important than that of the $\Phi$. Although, increased $\Phi$ produces gases with higher gross heating value, the energy recovery decreases with increased $\Phi$ due to higher tar and char production.

(5) The quality of the product gases is higher with DB: coal blend than with the gasification of pure DB due to higher quality of VM, higher peak temperature, and more $\mathrm{CO}$ production for the blend.

\section{Acknowledgment}

The financial support from DOE-NREL Golden, CO, USA, is gratefully acknowledged.

\section{References}

[1] M. L. Hobbs, P. T. Radulovic, and L. D. Smoot, "Combustion and gasification of coals in fixed-beds," Progress in Energy and Combustion Science, vol. 19, no. 6, pp. 505-586, 1993.

[2] A. V. Bridgwater, "The technical and economic feasibility of biomass gasification for power generation," Fuel, vol. 74, no. 5, pp. 631-653, 1995.
[3] E. Bahman, "Nitrogen mineralization from field-applied beef cattle feedlot manure or compost," Soil Science Society of America Journal, vol. 64, no. 6, pp. 2024-2030, 2000.

[4] Department of Primary Industries and Fisheries (DPI\&F), Feedlot Waste Management Series: Manure Production Data, Government of Queensland, Australia, 2003.

[5] N. T. Carlin, K. Annamalai, H. Oh et al., "Co-combustion and gasification of coal and cattle biomass: a review of research and experimentation," International Journal of Green Energy, vol. 4, pp. 133-159, 2008.

[6] K. P. Raman, W. P. Walawender, and L. T. Fan, "Gasification of feedlot manure in a fluidized bed reactor. The effect of temperature," Industrial \& Engineering Chemistry Process Design and Development, vol. 19, no. 4, pp. 623-629, 1980.

[7] S. Priyadarsan, K. Annamalai, J. M. Sweeten, M. T. Holtzapple, and S. Mukhtar, "Co-gasification of blended coal with feedlot and chicken litter biomass," Proceedings of the Combustion Institute, vol. 30, pp. 2973-2980, 2005.

[8] G. Gordillo, K. Annamalai, and N. Carlin, "Adiabatic fixed-bed gasification of coal, dairy biomass, and feedlot biomass using an air-steam mixture as an oxidizing agent," Renewable Energy, vol. 34, no. 12, pp. 2789-2797, 2009.

[9] G. Gordillo and K. Annamalai, "Adiabatic fixed bed gasification of dairy biomass with air and steam," Fuel, vol. 89, no. 2, pp. 384-391, 2010.

[10] G. Gordillo and K. Annamalai, "Air-steam gasification of dairy biomass using small scale fixed bed gasifier," in Proceedings of the ASME Turbo Expo, pp. 357-366, Orlando, Fla, USA, June 2009.

[11] G. Gordillo, Fixed bed counter-current low temperature gasification of dairy biomass and coal-dairy biomass blends using airsteam as oxidizer, Ph.D. thesis, Texas A\&M University, College Station, Tex, USA, 2009.

[12] K. Annamalai and I. Puri, Combustion Science and Engineering, CRC Press, Boca Raton, Fla, USA, 2007. 

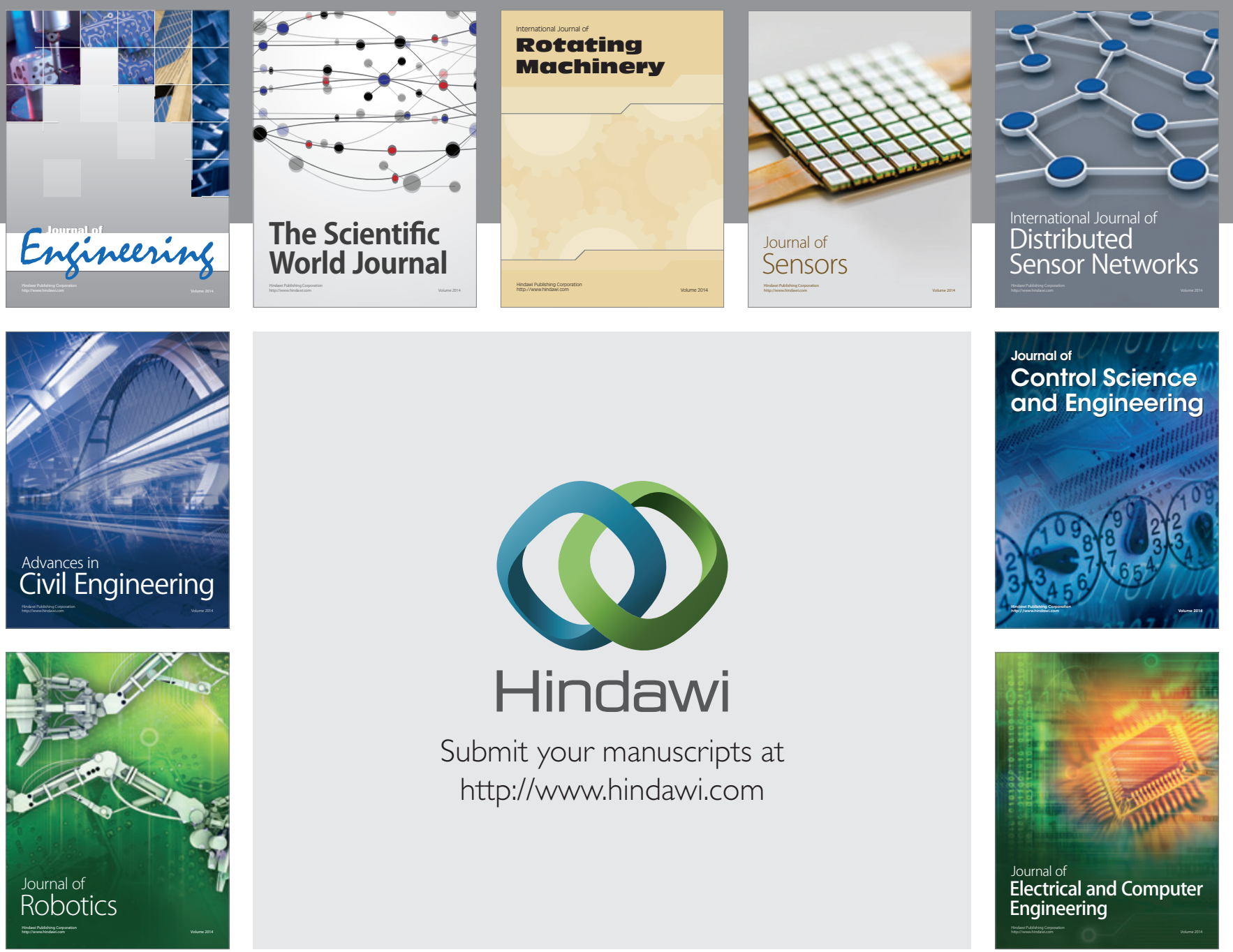

Submit your manuscripts at

http://www.hindawi.com
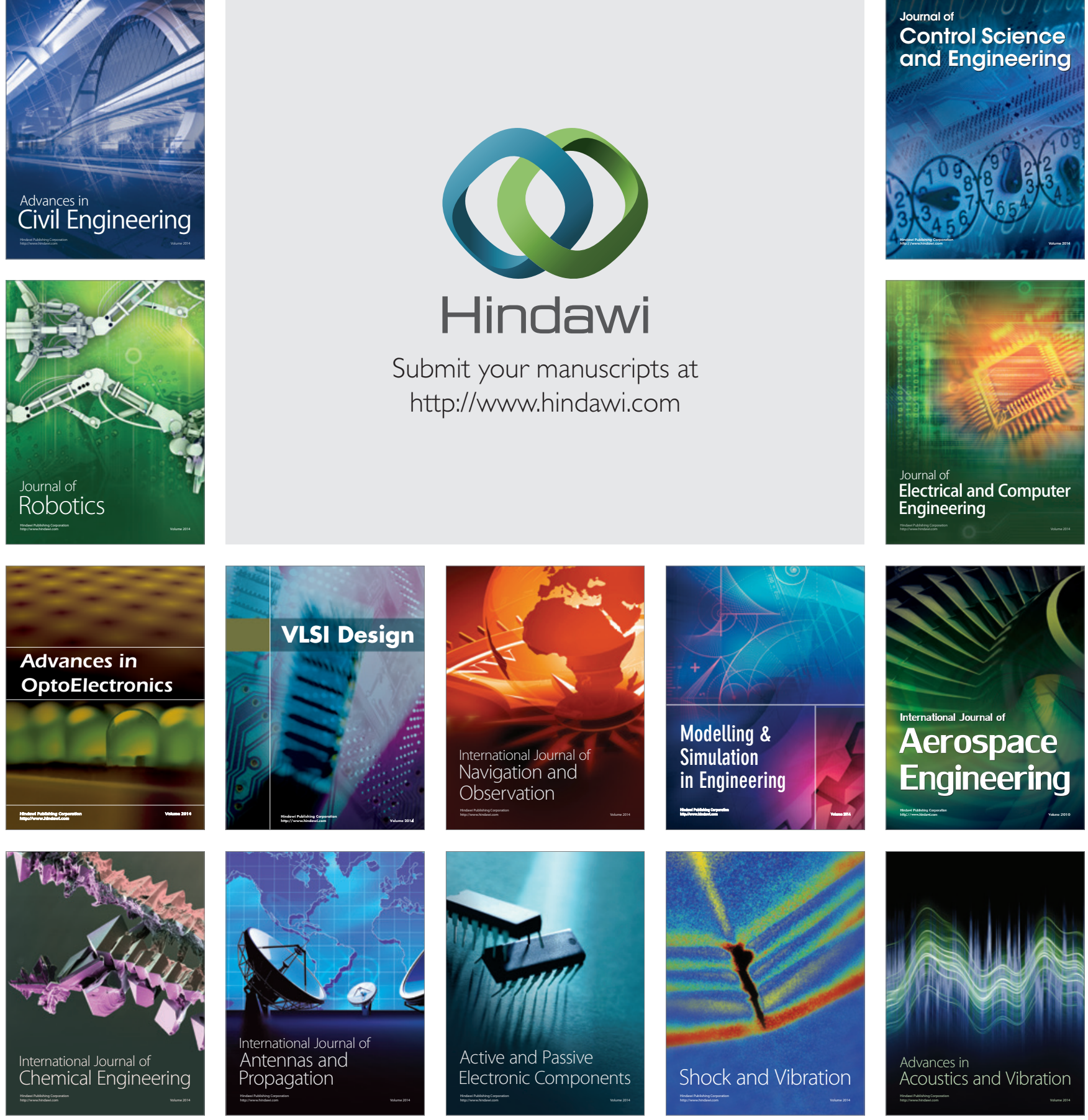